\title{
Gastrointestinal Motility, Part 2: Small-Bowel and Colon Transit
}

\author{
Alan H. Maurer \\ Nuclear Medicine and Molecular Imaging, Temple University Hospital and School of Medicine, Philadelphia, Pennsylvania
}

\begin{abstract}
CE credit: For CE credit, you can access the test for this article, as well as additional JNMT CE tests, online at https://www.snmmilearningcenter.org. Complete the test online no later than March 2019. Your online test will be scored immediately. You may make 3 attempts to pass the test and must answer $80 \%$ of the questions correctly to receive $1.0 \mathrm{CEH}$ (Continuing Education Hour) credit. SNMMI members will have their CEH credit added to their VOICE transcript automatically; nonmembers will be able to print out a CE certificate upon successfully completing the test. The online test is free to SNMMI members; nonmembers must pay $\$ 15.00$ by credit card when logging onto the website to take the test.
\end{abstract}

Because of the difficulty often encountered in deciding whether a patient's symptoms originate in the upper or lower gastrointestinal tract, gastrointestinal transit scintigraphy is a uniquely suited noninvasive, quantitative, and physiologic method of determining whether there is a motility disorder affecting the stomach, small bowel, or colon. Small-bowel and colon transit studies can be performed alone or together with gastric emptying studies after oral administration of an appropriately radiolabeled meal. It is hoped that newly published standards for performing these studies and the anticipated arrival of new Current Procedural Terminology codes in the United States for small-bowel and colon transit studies will increase their availability and use.

Key Words: gastrointestinal scintigraphy; small-bowel transit scintigraphy; colon transit scintigraphy; whole-gut transit scintigraphy

J Nucl Med Technol 2016; 44:12-18

DOI: 10.2967/jnumed.113.134551

\section{D} yspeptic symptoms related to dysmotility originating from the small bowel or colon usually include abdominal pain, diarrhea, or constipation. In many cases, however, symptoms overlap and it is difficult to differentiate whether they originate in the upper or lower gastrointestinal tract or both. Studies of small-bowel motility have shown a correlation between small-bowel contractions and severity of symptoms in gastroparesis (1). Indications for small-bowel and colon transit scintigraphy include but are not limited to dyspepsia, irritable bowel syndrome, chronic constipation, chronic diarrhea, chronic idiopathic intestinal pseudoobstruction, scleroderma, celiac disease, and malabsorption. Small- and large-bowel motility is the

\footnotetext{
Received May 19, 2015; revision accepted Jun. 15, 2015.

For correspondence or reprints contact: Alan H. Maurer, Nuclear Medicine and Molecular Imaging, Temple University Hospital and School of Medicine, Broad and Ontario Streets, Philadelphia, PA 19140.

E-mail: amaurer@temple.edu

COPYRIGHT (C 2016 by the Society of Nuclear Medicine and Molecular Imaging, Inc.
}

result of complex gastrointestinal contractions that promote the aboral movement of intestinal chyme and indigestible solids. It is recommended that gastrointestinal transit studies be used to localize the potential site of disease and guide therapy (2). A final diagnosis of a primary motility disorder by scintigraphy should not be made until an anatomic or structural cause (e.g., tumor, stricture, malrotation) for abnormal transit has been excluded by imaging or endoscopy.

Nonscintigraphic methods of measuring bowel transit include hydrogen breath tests for small-bowel transit and radioopaque markers for colon transit. Wireless motility capsules measure $\mathrm{pH}$, pressure, and temperature throughout the gastrointestinal tract and are capable of measuring gastric emptying time, small-bowel transit time, and colon transit time. Indigestible solids such as radioopaque markers $(4 \mathrm{~mm})$ and the wireless motility capsule $(27 \times$ $12 \mathrm{~mm}$ ) do not move through the gastrointestinal tract in the same manner as a physiologic meal $(3,4)$. The American Neurogastroenterology and Motility Society task force on gastrointestinal transit has stated that "the scintigraphic method is the only one that reliably allows the determination of both total and regional transit times" for gastrointestinal and colon transit (2). In a more recent report, this same organization together with the European Society of Neurogastroenterology and Motility have stated that scintigraphy is recommended for "detection of altered small-intestine transit in subjects with a suspected diffuse gastrointestinal motility disorder" and that colon transit scintigraphy "offers reproducible and accurate performance." This report further states that scintigraphy "is indicated to measure whole gut and regional colon transit in patients with suspected colon motility disorders or more diffuse disorders involving the stomach or small intestine" (5).

Although scintigraphic methods for measuring small-bowel and colon transit have been in use for at least $20 \mathrm{y}$, they have not gained widespread clinical use, in large part because of their lack of standardization. The recently published joint guideline of the Society of Nuclear Medicine and Molecular Imaging (SNMMI) and the European Association of Nuclear 
Medicine (EANM) has been recognized as an important "step toward standardization" (6). As an additional impediment to wider clinical use in the United States, there have been no Current Procedural Terminology (CPT) codes available for reporting and reimbursement. New codes have recently been presented to and accepted by the American Medical Association CPT Panel. It is anticipated that these will soon be available.

\section{GENERAL METHODOLOGY}

Like the esophageal transit and gastric emptying studies described in part 1 of this article, small-bowel and colon gastrointestinal transit studies most commonly use ${ }^{99 \mathrm{~m}} \mathrm{Tc}$ and ${ }^{111} \mathrm{In}$ as the radioisotope. ${ }^{67} \mathrm{Ga}$ complexes have also been used for colon transit studies, which extend over several days (7).

The reader is referred to the recently published SNMMI and EANM Practice Guideline for Small-Bowel and Colon Transit for a more in-depth description of the technical details of performing these studies, including patient preparation, image acquisition, and image processing (8). This review highlights the technical details of performing scintigraphic small-bowel and colon transit studies and describes normal and abnormal physiology and important imaging findings in interpreting these studies.

Small-bowel and colon transit scintigraphy is typically performed alone or, with minor modifications, as a continuation of a gastric emptying study. Three methods have been reported. The most common uses a mixed solid-liquid gastric emptying meal $(7,8)$, with the liquid phase being radiolabeled with ${ }^{111}$ In-diethylenetriaminepentaacetic acid (DTPA). As the liquid mixes with intestinal chyme, transit of the radiopharmaceutical is viewed to assess small-bowel and colon transit. If a solid-phase gastric emptying study is not requested, a solid meal is administered but without radiolabeling to maintain the standardized meal content. A second method uses a specially prepared, delayed-release, methacrylate resin-coated capsule containing ${ }^{111}$ In-labeled activated charcoal particles. The coated capsule dissolves on reaching the alkaline terminal ileum, releasing the radioisotope into the lumen for subsequent measurement of colon transit (9). The third substitutes ${ }^{67} \mathrm{Ga}$-complexes for ${ }^{111}$ In-DTPA as part of a mixed solidliquid meal $(10,11)$.

\section{SMALL-BOWEL TRANSIT STUDIES}

Measurement of small-bowel transit is complex because entry of a meal into the small intestine depends on gastric emptying and because small-bowel chyme spreads over a large distance as it progresses toward the colon. The function of the small bowel is to transport food as it empties from the stomach and to mix it with bile and with pancreatic and intestinal secretions to facilitate absorption over the bowel mucosal surface. There is no simple small-bowel peristaltic pattern. Antegrade and retrograde movements of intestinal chyme occur in the jejunum and ileum, with some areas progressing rapidly and others slowly. Jejunal peristaltic activity is typically more rapid and intense, with slowing of peristalsis seen in the ileum (9). This process, although irregular, results in a net overall progression of chyme toward the colon. Periodic more organized peristaltic contractions occur, originating in the stomach and propagating throughout the small intestine. These specialized contractions, known as the migrating motor complex, serve a housekeeping role by sweeping undigested material through the intestines. Although more rapid peristalsis and transit occur in the duodenum and jejunum, the content of the small bowel slows particularly in the terminal ileum before passing the ileocecal valve and moving into the colon. The result is a buildup of radiotracer activity in the terminal ileum, which functions as a reservoir for chyme before it passes into the colon (Fig. 1) (10).

The ileocolonic junction between the terminal ileal reservoir and the cecum regulates the flow of intestinal chyme from the small bowel into the colon (Fig. 2A). Studies on animals and humans have confirmed that pulsatile filling of the cecum is associated with propagating ileal contractions. The daily flow of chyme across the ileocolonic junction is estimated at 1-2 L, with increased flow seen postprandially (11). Early scintigraphic studies that demonstrated discrete bolus transfers of intestinal chyme across the ileocolonic junction also showed that such bolus transfers are more frequent within the first hour after a meal than during the fasting state (12). More recently, scintigraphy has been combined with manometric pressure recordings to measure flow across the ileocecal valve. By direct instillation of radioisotope through a nasocolonic catheter that has multiple recording sites extending from the terminal ileum to the proximal colon, discrete episodic movements of luminal

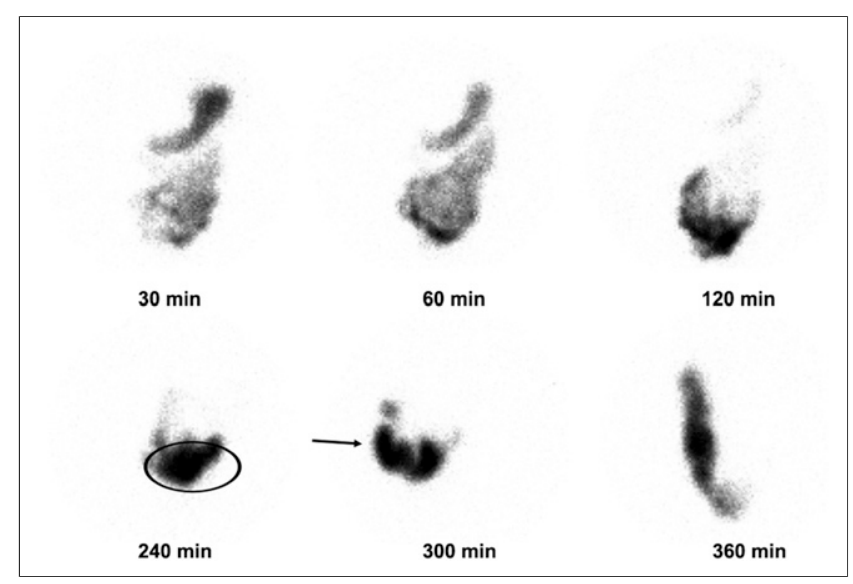

FIGURE 1. Sequential gastric emptying images showing normal small-bowel transit after liquid ${ }^{111}$ In-DTPA meal (anterior views). Early diffuse small-bowel activity later progressively accumulates in terminal ileum reservoir (oval region of interest). More than $60 \%$ of total activity is already in terminal ileum by $4 \mathrm{~h}(240 \mathrm{~min})$, followed by further progression into cecum-ascending colon (arrow) at $6 \mathrm{~h} \mathrm{(300} \mathrm{min)} \mathrm{and} \mathrm{then} \mathrm{progressive} \mathrm{filling} \mathrm{of} \mathrm{ascending}$ colon, with $100 \%$ of activity having completed transit through small bowel at $6 \mathrm{~h}$ (360 min). 
FIGURE 2. (A) Demonstration of how location of ileocolonic junction is defined scintigraphically in relationship to terminal ileum and proximal colon (top) and how regions of interest (bottom) have been defined to study coordination of manometric pressure recordings with luminal flow. (B) Serial images illustrating how radiotracer activity in terminal ileum and cecum can be linked to simultaneous pressure recordings. With this technique, both antegrade and retrograde flow across ileocolonic junction has been observed. Transient retrograde flow can occur across ileocecal valve, but ileum is capable of rapidly clearing any colon reflux. Several studies have shown that ileal propagative waves coordinate with cecal propagating waves. (Reprinted with permission of (13).)

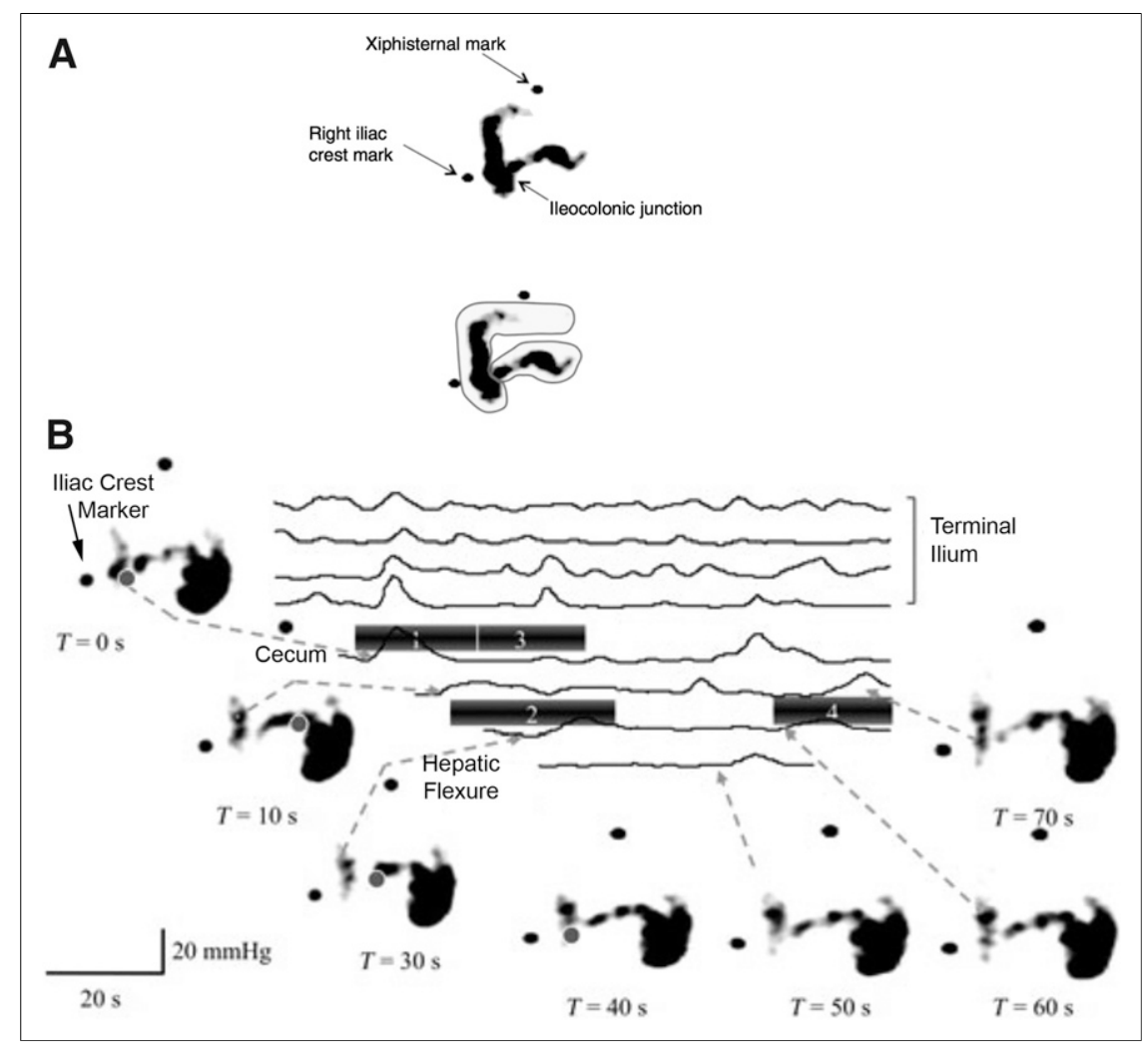

flow have been recorded (Fig. 2B) (13). Such studies have further demonstrated the role of the terminal ileum in initially storing intestinal chyme before permitting flow into the colon.

The simplest conceptual approach to scintigraphic measurement of small-bowel transit is to measure orocecal transit time by imaging the leading edge of radiotracer transit through the bowel. Accurately defining the leading edge (the first visualized arrival of activity in the cecum), however, requires frequent (every 10-15 min) and prolonged imaging because of the stasis in the terminal ileum. Hydrogen breath testing, which measures leading-edge transit, correlates well with scintigraphy. In one study, orocecal transit times were $56 \pm 4$ min for lactulose breath testing and $43 \pm 4$ min for simultaneously performed scintigraphy. However, lactulose itself speeds small-bowel transit and accelerates orocecal transit. Without lactulose, the scintigraphic orocecal transit time was $231 \pm 37 \min (14)$.

Small-bowel orocecal transit time will vary with the meal administered. When measured using resin pellets mixed with a meal, orocecal transit time in healthy individuals ranged from 151 to $290 \mathrm{~min}$ (18). When measured using the liquid phase of a mixed solid-liquid meal, small-bowel transit time ranged from 72 to $392 \mathrm{~min}$ in healthy individuals (15). In some cases there may be a prolonged stasis of activity in the terminal ileal reservoir, particularly when no second meal is administered, resulting in the need for impractically prolonged imaging beyond $6 \mathrm{~h}$ to see activity progress into the cecum or ascending colon.
An alternative scintigraphic method of measuring smallbowel transit does not attempt to characterize the complex temporal or spatial peristaltic small-bowel patterns or leading-edge transit but simply measures the overall bulk movement of radiotracer as it progresses distally into the terminal ileum. Typically, the orally administered radiolabeled meal collects in the terminal ileal reservoir, which is identified as an area of progressively increasing counts before the cecum or ascending colon is seen (Fig. 1). This region is also referred to as the ileocolonic junction $(16,17)$. The progressive buildup of activity in the terminal ileum can easily be measured and used as an index of small-bowel motility (18). The recent SNMMI/EANM guideline on small-bowel transit recommends use of the percentage of administered liquid meal that has accumulated in the terminal ileum at $6 \mathrm{~h}$ after meal ingestion as a simple index of small-bowel transit. Small-bowel transit is considered normal if more than $40 \%$ of administered activity has progressed into the terminal ileum or passed into the cecum and ascending colon at $6 \mathrm{~h}$ (Fig. 1) (19). Small-bowel transit is typically considered delayed if activity persists in multiple loops of small bowel at $6 \mathrm{~h}$ and little $(<40 \%)$ to no activity arrives in the terminal ileum reservoir (Fig. 3 ).

The amount of colon filling at $6 \mathrm{~h}$ has also been used as an index of small-bowel transit. The range for normal filling of the colon at $6 \mathrm{~h}$ using nondigestible particles is $11 \%-$ $70 \%$. The range for digestible solids is $43 \%-95 \%$, with rapid small-bowel transit defined as a cecal arrival time of less than $90 \mathrm{~min}(20)$. 


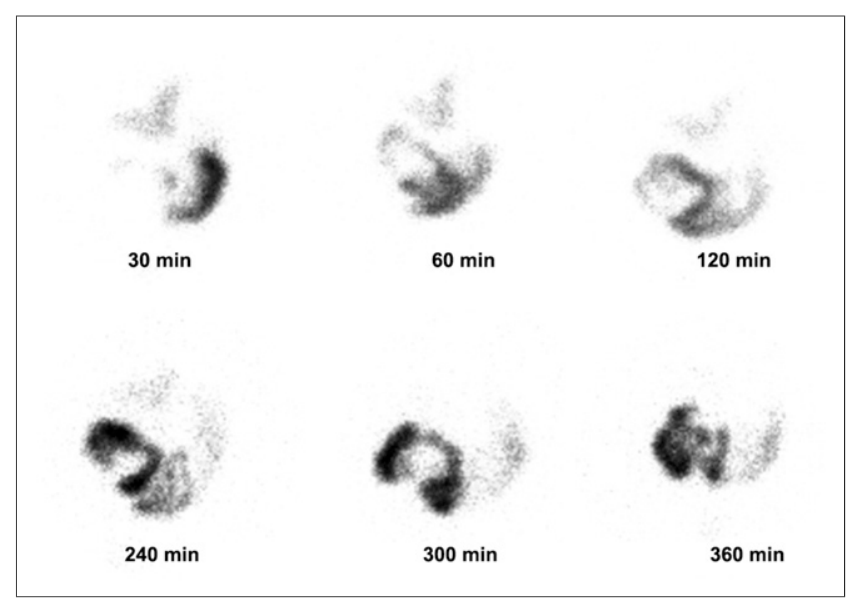

FIGURE 3. Delayed small-bowel transit after liquid ${ }^{111}$ In-DTPA meal (anterior views ). In contrast to Figure 1, small-bowel transit is delayed, with images showing persistent, diffuse activity within multiple proximal loops of small bowel and no arrival of activity in terminal ileum reservoir or ileocolonic junction by $6 \mathrm{~h}$.

Deconvolution analysis of bowel transit was first introduced by Malagelada in 1984 to correct for how the rate of gastric emptying affects small-bowel transit measurement (21). A modified approach was later proposed by Brinch in 1999 (22). These methods yield an expected small-bowel timeactivity curve based on instantaneous gastric emptying. The curve can be used to calculate a mean transit time for the bulk of radiolabeled material. Deconvolution methods, however, require frequent (every $30 \mathrm{~min}$ ) imaging and lengthy acquisitions until all tracer has passed into the colon. A further simplification to deconvolution was proposed by Read in 1986 and is based on subtraction of $50 \%$ gastric emptying time from the time to $50 \%$ colon filling (17).

\section{COLON TRANSIT STUDIES}

The ileocolonic junction controls how the liquid small-bowel contents enter the colon. The motility of the colon controls slow mixing and movement of its contents so the colon can absorb water and liquids can be transformed to semisolids or solids in the sigmoid colon. Ultimately, controlled defecation occurs 1-2 times daily in healthy individuals. Three distinct colon contraction patterns with different spatiotemporal patterns have been described. Rhythmic phasic contractions aided by tonic contractions cause slow distal propulsion and mixing. Infrequent giant migrating contractions produce mass movements.

Therapy for patients with chronic constipation depends on identifying whether there is colon inertia, generalized slow colon transit, pelvic floor dysfunction, functional outlet obstruction, or irritable bowel syndrome. Colon motility is tested to determine whether a patient with symptoms of constipation has abnormal colon transit and whether a specific area of the colon is involved $(23,24)$. Invasive manometric and myoelectric devices for studying colon transit are inconsistent and difficult to use and have a limited number of recording sites. Colon transit can be imaged using serial radiographs and radiopaque markers. Radiographic markers are ingested with a meal, and radiographs are obtained to count the number of markers in segments of the colon. Such markers, however, are not physiologic compared with transit of intestinal chyme. The rate of transit of solid particles depends on their size, and intracolonic visualization and localization can be difficult given the limited anatomic landmarks. Radiopaque markers, however, have been shown to correlate well with scintigraphic measurement of colon transit $(25,26)$. The wireless motility capsule is also used to measure colon transit. The colon transit time is the time from entry of the capsule into the cecum, determined by a sudden drop in $\mathrm{pH}$, to the time the capsule passes out of the colon, determined by a sudden drop in temperature accompanied by loss of pressure recording. In a large multicenter study of constipated patients that compared the wireless motility capsule to radiopaque markers, overall agreement in classifying patients as having either slow or normal colon transit was $87 \%$ (27). Colon transit scintigraphy is indicated for measuring transit time in patients with constipation or diarrhea and can be used as a marker to validate new treatments and to direct patient care $(19,28)$.

Both ${ }^{111}$ In-DTPA (2.8-d half-life) and ${ }^{67}$ Ga-citrate (3.2-d halflife), when given orally for colon transit scintigraphy, are nonabsorbable and have half-lives long enough to permit several days of imaging. ${ }^{111}$ In-DTPA is typically available as a sterile, single-use vial for intrathecal administration. Most centers that perform colon transit studies administer it orally in divided doses to keep unit-dose expenses low. ${ }^{67} \mathrm{Ga}$-citrate has been used as an alternative because of lower cost and good availability and lower whole-body radiation exposure (Table 1), which is of particular concern for pediatric use (29).

Two methods that use oral ${ }^{111}$ In-DTPA to measure colon transit have been most commonly applied. The reader is referred to the recent SNMMI and EANM Practice Guideline for Small-Bowel and Colon Transit for more complete technical details (8). One method (Mayo Clinic) requires preparation of a resin-coated capsule designed to dissolve at a $\mathrm{pH}$ of 7.2-7.4 in the environment of the ileum ( $\mathrm{pH} 7.4)$ (12). An alternate method (Temple University), which does not require fabrication of a special capsule, is to use ${ }^{111}$ In-DTPA as part of a standard solid-liquid gastric emptying meal (18). To quantitate colon transit, the geometric center has been defined as a measure of the progression of colon radiotracer activity. To calculate the geometric center, the colon is divided into anatomic regions, each of which has a numeric value. With the solid-liquid meal method, a 7-segment analysis includes cecum-ascending colon, hepatic flexure, transverse colon, splenic flexure, descending colon, rectosigmoid colon, and excreted stool. The geometric center is a weighted average of the counts in each region (Fig. 4). A low geometric center (1 to 2) indicates that the center of activity is in the proximal colon, and a higher geometric center ( 5 to 7 ) indicates that the activity has progressed to the left side of the colon or has 
TABLE 1

Comparison of Adult Dose Estimates for Oral ${ }^{111}$ In-DTPA vs. ${ }^{67}$ Ga-Citrate

\begin{tabular}{|c|c|c|c|c|}
\hline \multirow[b]{2}{*}{ Radiopharmaceutical } & \multirow[b]{2}{*}{ Dose (MBq) } & \multirow[b]{2}{*}{ Effective dose (mSv) } & \multicolumn{2}{|c|}{$\begin{array}{c}\text { Absorbed dose in lower large } \\
\text { intestine (mSv) }\end{array}$} \\
\hline & & & Normal & Constipated \\
\hline${ }^{111}$ In-DTPA & 4 & 1.20 & 6.4 & 11.6 \\
\hline${ }^{67} \mathrm{Ga}$-citrate & 4 & 0.74 & 6.5 & 11.8 \\
\hline Modified from (7). & & & & \\
\hline
\end{tabular}

been eliminated in stool. A simpler 5-segment region analysis has also been described (8). Using the geometric center, a simple single numeric value is applied to measure transit of activity through the colon.

For the mixed solid-liquid meal method, colon images are acquired at 24,48 , and $72 \mathrm{~h}$. If the geometric center at $48 \mathrm{~h}$ is less than 4.1 (proximal to the splenic flexure), no further imaging is needed because colon transit is delayed. If the geometric center is greater than 4.1 but less than 6.4 , imaging should be performed at $72 \mathrm{~h}$ to exclude functional outlet obstruction. The normal mean values $( \pm \mathrm{SD})$ for geometric center are $4.6 \pm 1.5$ at $24 \mathrm{~h}, 6.1 \pm 1.0$ at $48 \mathrm{~h}$, and $6.6 \pm 0.19$ at $72 \mathrm{~h}$.

There are 3 major patterns of slow colon transit: generalized slow transit with diffuse retention throughout the length of the colon, marked right-sided retention proximal to the splenic flexure (colon inertia), and retention in the rectosigmoid (functional rectosigmoid obstruction) (Fig. 5) (30).

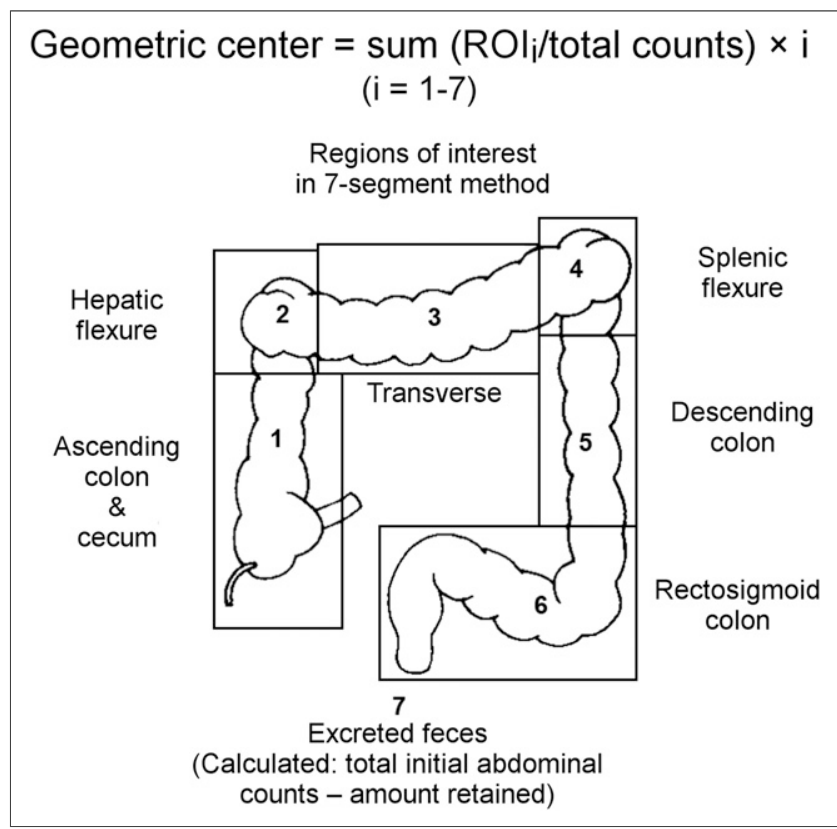

FIGURE 4. Colon geometric center analysis. Six regions of interest are used to define each segment and formula for calculation.
In adults with diarrhea, accelerated colon transit can be confirmed by finding that the geometric center is greater than 6.1 (at or beyond the rectosigmoid colon) at $24 \mathrm{~h}$. Colon transit studies in pediatric patients with chronic constipation show a subgroup who have rapid proximal colon transit $(>25 \%$ of the tracer is beyond the hepatic flexure at $6 \mathrm{~h}$ or $>25 \%$ is beyond the end of the descending colon at $24 \mathrm{~h})(31)$.

\section{WHOLE-GUT TRANSIT STUDIES}

Whole-gut transit scintigraphy refers to a combined study that includes measurement of gastric emptying, small-bowel transit, and colon transit after administration of a dual-isotope, solid-liquid meal. These studies are helpful for evaluating patients whose symptoms cannot be classified as either upper or lower gastrointestinal in origin or when there is suspicion of a functional and nonorganic cause (e.g., structural, metabolic, myopathic, or neuropathic). In a study at the Mayo Clinic, $40 \%$ of patients

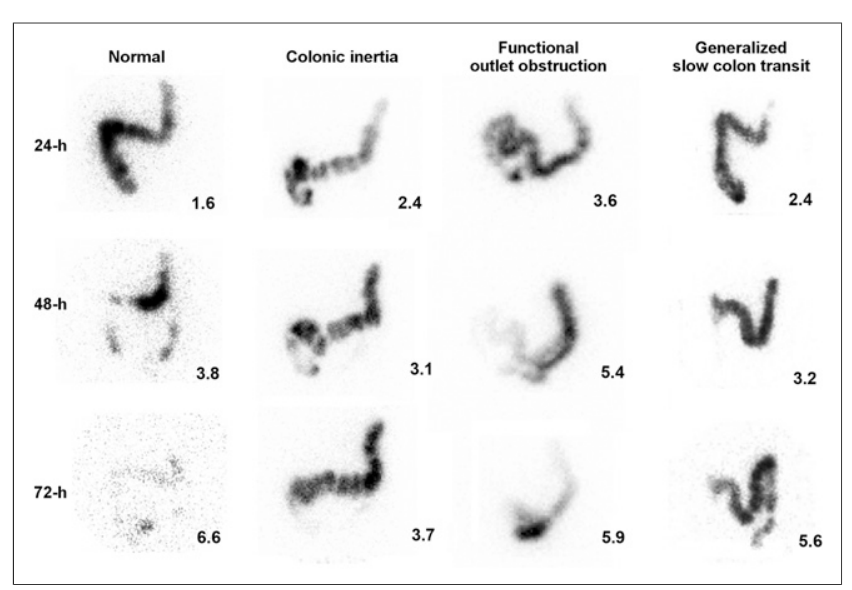

FIGURE 5. Normal and abnormal colon transit patterns. Normal colon transit is reflected by activity predominantly in right colon at $24 \mathrm{~h}$ and nearly complete emptying at $72 \mathrm{~h}$. Colon inertia is reflected by failure of activity to progress beyond splenic flexure at 48 and $72 \mathrm{~h}$. Functional rectosigmoid outlet obstruction is reflected by normal progression from right colon to left colon but with retention in rectosigmoid colon at $72 \mathrm{~h}$. Generalized slow colon transit is reflected by diffuse pattern of colon retention at $72 \mathrm{~h}$. 
referred for upper gastrointestinal symptoms, constipation, or diarrhea were found to have an organic cause of symptoms and $60 \%$ a functional cause (32). Colon transit is slowed more commonly in patients with organic disease and is normal in many patients with functional complaints of constipation. In a study to evaluate the clinical utility of whole-gut transit scintigraphy, organic disease was found in many patients with an initially suspected functional disorder. The initial diagnosis was changed in $45 \%$ of patients, and patient management was changed in $67 \%$ of patients (19).

Whole-gut transit scintigraphy "is indicated to measure whole gut and regional colon transit in patients with suspected colon motility disorders or more diffuse disorders involving the stomach or small intestine" (5).

Patients with diarrhea-predominant irritable bowel syndrome have a shorter small-bowel transit time and rapid colon filling, whereas constipated patients have a slower small-bowel transit time and delayed colon filling (17). Gastrointestinal symptoms in patients with untreated celiac disease are associated with a wide range of dysmotility involving esophageal transit, gastric and gallbladder emptying, orocecal transit (small bowel), and colon transit (33). Whole-gut scintigraphy, therefore, can play an important role in evaluating patients with suspected symptoms of celiac disease.

Whole-gut transit scintigraphy is most helpful for evaluating patients with constipation. Many patients with severe idiopathic constipation have prominent upper gastrointestinal symptoms. It is important to exclude significant upper gastrointestinal dysmotility in such patients before surgery because subtotal colectomy may not correct their symptoms (34). Colectomy should be performed only if transit abnormality is limited to the colon. In a study of patients with severe idiopathic constipation with upper gastrointestinal symptoms (12 constipated patients), 3 of 4 with upper gastrointestinal symptoms had abnormal gastric emptying and small-bowel transit in addition to delayed colon transit (35).

Intestinal pseudoobstruction is a severe motility disorder in which patients present with clinical signs of bowel obstruction. Radiographs will show dilated loops of bowel and air-fluid levels suggesting obstruction, but no mechanical occluding lesion can be found. The presence of delayed gastric emptying, delayed small-bowel transit, and slow colon transit seen on whole-gut transit scintigraphy helps to establish a diagnosis of idiopathic intestinal pseudoobstruction (36).

\section{CONCLUSION}

Because of the difficulty often encountered in deciding whether a patient's symptoms originate in the upper or lower gastrointestinal tract, gastrointestinal transit scintigraphy is a uniquely suited noninvasive, quantitative, and physiologic method of determining whether there is a motility disorder affecting the stomach, small bowel, or colon.
Small-bowel and colon transit studies can be performed alone or together with gastric emptying studies after oral administration of an appropriately radiolabeled meal. It is hoped that newly published standards for performing these studies and the anticipated arrival of new Current Procedural Terminology codes in the United States for smallbowel and colon transit studies will increase their availability and use.

\section{REFERENCES}

1. Barshop K, Staller K, Semler J, Kuo B. Duodenal rather than antral motility contractile parameters correlate with symptom severity in gastroparesis patients. Neurogastroenterol Motil. 2015;27:339-346.

2. Lin HC, Prather C, Fisher R, et al. Measurement of gastrointestinal transit: AMS task force committee on gastrointestinal transit. Dig Dis Sci. 2005;50: 989-1004.

3. Madsen JL, Larsen N, Hilsted J, Worning H. Scintigraphic determination of gastrointestinal transit times: A comparison with breath hydrogen and radiologic methods. Scand J Gastroenterol. 1991;26:1263-1271.

4. Southwell BR, Clarke M, Sutcliffe J, Hutson J. Colonic transit studies: normal values for adults and children with comparison of radiological and scintigraphic methods. Pediatr Surg Int. 2009;25:559-572.

5. Rao SS, Camilleri M, Hasler W, et al. Evaluation of gastrointestinal transit in clinical practice: position paper of the American and European Neurogastroenterology and Motility Societies. Neurogastroenterol Motil. 2011;23:823.

6. Mariani G, Paglianiti I. Joint SNMMI and EANM guideline for small-bowel and colon transit: important step towards long-awaited standardization. Eur J Nucl Med Mol Imaging. 2014;41:405-407.

7. Bellen JC, Chatterton B, Penglis S, Tsopelas C. Gallium-67 complexes as radioactive markers to assess gastric and colonic transit. J Nucl Med. 1995;36:513517.

8. Maurer A, Camilleri M, Donohoe K, et al. The SNMMI and EANM practice guideline for small-bowel and colon transit 1.0. J Nucl Med. 2013;54:20042013.

9. Seidl H, Gundling F, Pfeiffer A, Pehl C, Schepp W, Schmidt T. Comparison of small-bowel motility of the human jejunum and ileum. Neurogastroenterol Motil. 2012;24:e373-e380.

10. Phillips SF, Quigley EM, Kumar D, Kamath PS. Motility of the ileocolonic junction. Gut. 1988;29:390-406.

11. Kerlin P, Phillips S. Differential transit of liquids and solid residue through the human ileum. Am J Physiol. 1983;245:G38-G43.

12. Camilleri M, Colemont L, Philips S, et al. Human gastric emptying and colonic filling of solids characterized by a new method. Am J Physiol. 1989;257:G284G290.

13. Dinning PG, Szczesniak M, Cook I. Determinants of postprandial flow across the human ileocaecal junction: a combined manometric and scintigraphic study. Neurogastroenterol Motil. 2008;20:1119-1126.

14. Miller MA, Parkman H, Urbain J, et al. Comparison of scintigraphy and lactulose breath hydrogen test for assessment of orocecal transit: lactulose accelerates small bowel transit. Dig Dis Sci. 1997;42:10-18.

15. Maurer AH, Krevsky B. Whole-gut transit scintigraphy in the evaluation of small-bowel and colon transit disorders. Semin Nucl Med. 1995;25:326338.

16. Graff J, Brinch K, Madsen JL. Simplified scintigraphic methods for measuring gastrointestinal transit times. Clin Physiol. 2000;20:262-266.

17. Read NW, Al-Janabi MN, Holgate AM, Barber DC, Edwards CA. Simultaneous measurement of gastric emptying, small bowel residence and colonic filling of a solid meal by the use of the gamma camera. Gut. 1986;27:300308.

18. Krevsky B, Maurer AH, Niewiarowski T, Cohen S. The effect of verapamil on human intestinal transit. Dig Dis Sci. 1992;37:919-924.

19. Bonapace ES, Maurer AH, Davidoff S, Krevsky B, Fisher RS, Parkman HP. Whole gut transit scintigraphy in the clinical evaluation of patients with upper and lower gastrointestinal symptoms. Am J Gastroenterol. 2000;95:28382847.

20. Szarka LA, Camilleri M. Methods for the assessment of small-bowel and colonic transit. Semin Nucl Med. 2012;42:113-123. 
21. Malagelada JR, Robertson J, Brown M, et al. Intestinal transit of solid and liquid components of a meal in health. Gastroenterology. 1984;87:12551263.

22. Brinch K, Larsson H, Madsen J. A deconvolution technique for processing small intestinal transit data. Eur J Nucl Med. 1999;26:272-276.

23. Rao SS. Constipation: evaluation and treatment of colonic and anorectal motility disorders. Gastroenterol Clin North Am. 2007;36:687-711.

24. Lembo A, Camilleri M. Chronic constipation. N Engl J Med. 2003;349:13601368.

25. Kanamalla U, Bromer MQ, Maurer AH, et al. Comparison of colon transit scintigraphy and radioopaque markers in patients with constipation [abstract]. J Nucl Med. 2001;42 (suppl):86P.

26. Proano M, Camilleri M, Phillips S, Brown M, Thomforde G. Transit of solids through the human colon: regional quantification in the unprepared bowel. Am J Physiol. 1990;258:G856-G862.

27. Camilleri M, Thorne N, Ringel Y, et al. Wireless $\mathrm{pH}$-motility capsule for colonic transit: prospective comparison with radiopaque markers in chronic constipation. Neurogastroenterol Motil. 2010;22:874-882.

28. Camilleri M. Scintigraphic biomarkers for colonic dysmotility. Clin Pharmacol Ther. 2010;87:748-753.
29. Cook B, Lim E, Cook D, et al. Radionuclear transit to assess sites of delay in large bowel transit in children with chronic idiopathic constipation. J Pediatr Surg. 2005;40:478-483.

30. Krevsky B, Maurer A, Fisher R. Patterns of colonic transit in chronic idiopathic constipation. Am J Gastroenterol. 1989;84:127-132.

31. Yik YI, Cain T, Tudball C, Cook D, Southwell B, Hutson J. Nuclear transit studies of patients with intractable chronic constipation reveal a subgroup with rapid proximal colonic transit. $J$ Pediatr Surg. 2011;46:1406-1411.

32. Charles F, Camilleri M, Phillips SF, Thomforde GM, Forstrom LA. Scintigraphy of the whole gut: clinical evaluation of transit disorders. Mayo Clin Proc. 1995;70:113-118.

33. Tursi A. Gastrointestinal motility disturbances in celiac disease. J Clin Gastroenterol. 2004;38:642-645.

34. Kamm MA, Hawley P, Lennard-Jones J. Outcome of colectomy for severe idiopathic constipation. Gut. 1988;29:969-973.

35. van der Sijp JR, Kamm M, Nightingale J, et al. Disturbed gastric and small bowel transit in severe idiopathic constipation. Dig Dis Sci. 1993;38:837844.

36. Panganamamula KV, Parkman H. Chronic intestinal pseudo-obstruction. Curr Treat Options Gastroenterol. 2005;8:3-11. 